\title{
PENICILLIN RESISTANCE IN STAPHYLOCOCCI ISOLATED IN A CASUALTY DEPARTMENT
}

\author{
BY \\ DAVID J. B. ASHLEY* AND M. J. BRINDLE \\ From the United Liverpool Hospitals (David Lewis Northern Hospital), Liverpool
}

(RECEIVED FOR PUBLICATION NOVEMBER 16, 1959)

\begin{abstract}
The results of a series of antibiotic resistance tests on 118 strains of Staphylococcus aureus isolated from patients attending a casualty department are recorded. Forty-six per cent. of the strains were resistant to penicillin, $12 \%$ to streptomycin, $7.5 \%$ to tetracycline, and small numbers to the other antibiotics. It is suggested that tetracycline should be used in those infections which are sufficiently severe to merit antibiotic treatment.
\end{abstract}

The rapid progress of medical science is, in one instance at least, paralleled by the rapidity of the evolutionary progress of the antagonist, the pyogenic staphylococcus. When penicillin was first added to the range of weapons available for the fight against infection its advent was hailed as the dawn of a new era in the treatment of staphylococcal infections, which were one of the major problems of the surgeon. Initially this hope was fulfilled and staphylococci became less feared in surgical practice. Unfortunately, however, strains of staphylococci capable of producing an enzyme which destroyed penicillin soon began to appear. By 1951, only seven years after the introduction of penicillin into routine hospital practice, Rountree (1951) was able to find a high proportion of resistant strains in infections treated at a hospital out-patient department and three years later the same author (Rountree, Freeman, and Barbour, 1954) found that three-quarters of the strains of staphylococci isolated from hospital inpatients were resistant to this antibiotic. Since that time the situation has materially deteriorated ; in 1959 Goodier and Parry found that over $80 \%$ of the strains of staphylococci isolated from inpatients were resistant to penicillin, as were over half the strains isolated from out-patients.

It is, nevertheless, still common practice for penicillin to be used freely in the therapy of relatively minor infections, and Lowden (1955), in a textbook on the casualty department, refers only to penicillin resistance in the case of infections in hospital staffs and patients recently in hospital.

\footnotetext{
* Present address: Morriston Hospital, Swansea.
}

The present paper comprises a study of the antibiotic resistance of strains of Staphylococcus aureus isolated from minor infections of skin and subcutaneous tissue of patients attending the casualty department of the David Lewis Northern Hospital, Liverpool, between April and June, 1959. Swabs were taken at the first attendance or, in the case of closed lesions, at the time of incision. The series is, as far as possible, composed of consecutive cases all of which were seen for the first time with the infection to which the study relates. Infections among members of the hospital staff and in-patients attending other departments were excluded from the series.

\section{Method}

The swabs were inoculated on to blood agar plates and were incubated at $37^{\circ} \mathrm{C}$. for 24 hours. Colonies morphologically resembling Staphylococcus pyogenes, usually in pure culture, were identified by Gram staining and were tested for coagulase activity by the

TABLE I

RESULTS OF TESTS ON 118 STRAINS OF STAPHYLOCOCCI

\begin{tabular}{|c|c|c|c|c|}
\hline & & Open Lesion & Closed Lesion & Total \\
\hline $\begin{array}{l}\text { Penicillin .. } \\
\text { Streptomycin } \\
\text { Tetracycline } \\
\text { Chloram- } \\
\text { phenicol } \\
\text { Erythromy- } \\
\text { cin } \\
\text { Oleandro- } \\
\text { mycin } \\
\text { Novobiocin }\end{array}$ & $\begin{array}{l}\text { Resistant } \\
\text { Sensitive } \\
\text { Resistant } \\
\text { Sensitive } \\
\text { Resistant } \\
\text { Sensitive } \\
\text { Resistant } \\
\text { Sensitive } \\
\text { Resistant } \\
\text { Sensitive } \\
\text { Resistant } \\
\text { Sensitive } \\
\text { Resistant } \\
\text { Sensitive }\end{array}$ & $\begin{array}{rc}21 & (54 \%) \\
18 & (46 \%) \\
5 & (13 \%) \\
34 & (87 \%) \\
3 & (8 \%) \\
36 & (92 \%) \\
39 & (100 \%) \\
39 & (100 \%) \\
39 & (2 \%) \\
38 & (98 \%) \\
1 & (2 \%) \\
38 & (98 \%)\end{array}$ & $\begin{aligned} 33 & (43 \%) \\
46 & (57 \%) \\
9 & (11 \%) \\
70 & (89 \%) \\
6 & (7 \cdot 5 \%) \\
73 & (92 \cdot 5 \%) \\
79 & (100 \%) \\
79 & - \\
79 & (100 \%) \\
2 & (2 \cdot 5 \%) \\
77 & (97.5 \%) \\
1 & (1 \cdot 2 \%) \\
78 & (98 \cdot 8 \%)\end{aligned}$ & $\begin{aligned} 54 & (46 \%) \\
64 & (54 \%) \\
14 & (12 \%) \\
104 & (88 \%) \\
9 & (7 \cdot 5 \%) \\
111 & (92 \cdot 5 \%) \\
118 & (100 \%) \\
118 & \overline{(100 \%)} \\
118 & (100 \%) \\
3 & (2 \cdot 5 \%) \\
115 & (97 \cdot 5 \%) \\
2 & (1.7 \%) \\
116 & (98 \cdot 3 \%)\end{aligned}$ \\
\hline
\end{tabular}


TABLE II

INCIDENCE OF PENICILLIN-RESISTANT STRAINS

\begin{tabular}{l|c|c|c|c}
\hline & & Open Lesion & Closed Lesion & Total \\
\hline Not on peni- & Resistant & $12(46 \%)$ & $24(36 \%)$ & $36(39 \%)$ \\
cillin & Sensitive & $14(54 \%)$ & $42(64 \%)$ & $56(61 \%)$ \\
On penicillin & Resistant & $9(69 \%)$ & $9(69 \%)$ & $18(69 \%)$ \\
& Sensitive & $4(31 \%)$ & $4(31 \%)$ & $8(31 \%)$ \\
\hline
\end{tabular}

slide technique of Williams and Harper (1946) using human plasma. All coagulase-positive staphylococci were tested for sensitivity to penicillin, streptomycin, tetracycline, erythromycin, oleandomycin, and novobiocin. The organisms were subcultured on to nutrient agar so as to produce a profuse growth and either "sentest" tablets (Evans) or "multodisks" (Oxoid) were placed on the surface of the medium before incubation. Sensitive organisms showed a zone of inhibition round the centre of the tablet or disc of at least $1 \mathrm{~cm}$. in diameter; resistant organisms showed a profuse growth right up to the edge of the disc.

One hundred and eighteen strains of staphylococci were tested by this method and the results are summarized in Table I. Twenty-six of the patients from whom these organisms had been isolated had been treated with penicillin in all cases before the swabs were taken and before bacterial sensitivity tests had been carried out. In these the severity of the local infection and the presence of evidence of extension of the infective process along the lymphatic channels indicated some form of therapy in addition to surgical intervention and local applications. In Table II the incidence of penicillin-resistant strains is compared in the two groups, those receiving and those not receiving penicillin.

\section{Discussion}

There has been over the years a steady increase in the proportion of strains of penicillin-resistant staphylococci from infected lesions in hospitals. Outside the hospital the process has been less rapid, partly because the majority of staphylococci either live in a state of precarious symbiosis with their hosts or cause minor infections not deemed worthy of the antibiotic sledge-hammer, and partly because cross-infection with drug-resistant strains is less likely to occur. Nevertheless in the last 10 years reports have appeared which indicate that the incidence of penicillin-resistant infection among hospital out-patients is steadily increasing (Fig. 1).

We are tolerably certain that the infections which caused the patients in the present investigation to seek treatment in hospital were contracted in the course of their normal daily lives, and that the organisms cannot be regarded as hospital staphylococci. In 26 instances the patients had been treated with penicillin and the incidence of penicillin-resistant infection in this group was significantly higher than in the remainder.

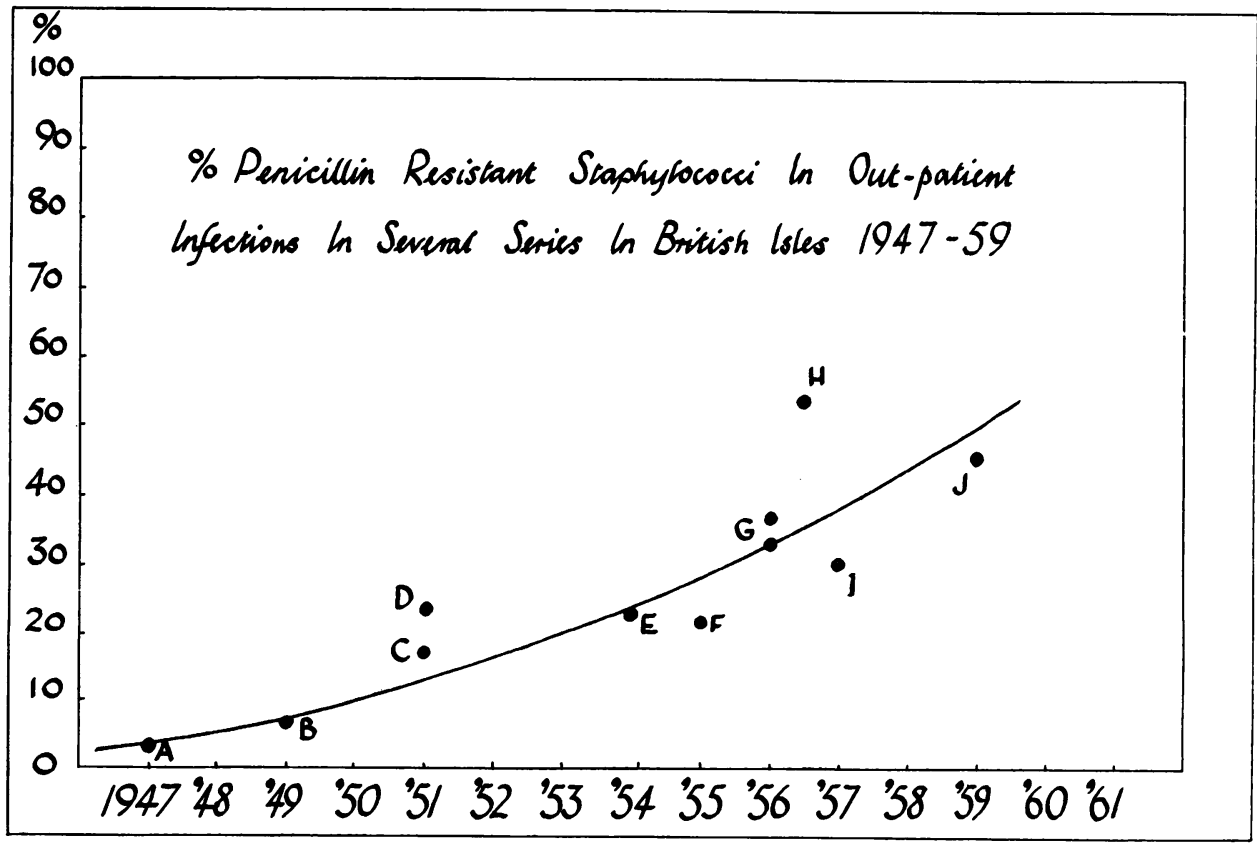

FIG. 1.-The increase in penicillin-resistant staphylococci in out-patient infections in a British series 1947-59. A, Bolton et al. (1947); B, Griffiths et al. (1949); C, Birnstingl et al. (1952); D, Summers (1952); E, Roodyn (1954); F, Rees et al. (1955); G, Fairbrother (1956); H, Goodier and Parry (1959); I, Buhr and Scott (1959); J, present series. 
The alternative antibiotics available for the treatment of staphylococcal infections are streptomycin, chloramphenicol, the tetracyclines, the erythromycin group, and novobiocin. The two latter should be reserved for staphylococcal infection resistant to other antibiotics, and the ease with which all bacteria, including staphylococci and tubercle bacilli, become resistant to streptomycin make its extensive use in casualty departments undesirable, so that the only alternative to penicillin is one of the tetracycline antibiotics.

We therefore urge a change in the treatment of staphylococcal infections in the casualty department and in general practice. First, antibiotics should be eschewed as far as possible and the purulent lesions should be treated on general surgical lines. Secondly, if the infection is of such severity and has spread so far that antibiotio therapy is indicated, bacteriological examinatio $\overrightarrow{\overrightarrow{\mathrm{F}}}$ and sensitivity tests should precede the administrat: tion of any antibiotic.

\section{REFERENCES}

Birnstingl, M. A., Shooter, R. A., and Hunt, M. F. (1952). Brit. meब. J., 2, 253.

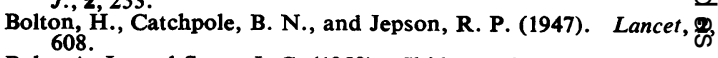

Buhr, A. J., and Scott, J. C. (1959). Ibid., 1, 1019.

Fairbrother, R. W. (1956). Ibid., 1, 716.

Goodier, T. E. W., and Parry, W. R. (1959). Ibid., 1, 356.

Griffiths, E., Jones, P. F., Shooter, R. A., and Heady, J. A. (1949) Brit. med. J., 2, 958 .

Lowden, T. G. (1955). The Casualty Department, p. 96. Living stone, Edinburgh.

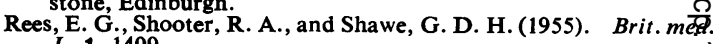
J., 1, 1409 .

Roodyn, L. (1954). Ibid., 2, 1322.

Rountree, P. M. (1951). Med. J. Aust., 2, 766.

ount., 2, 766.

Summers, G. A. C. (1952). Lancet, 1, 135. H. (1954). Ibid., 2, 45t)

Williams, R. E. O., and Harper, G. J. (1946). Brit. J. exp. Path., 24? 72 . 